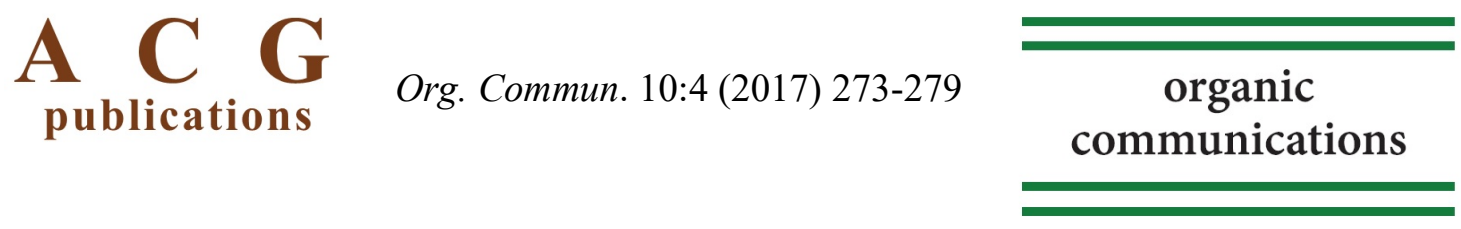

\title{
An intermolecular Diels-Alder cycloaddition under various condition between 1,3-cyclohexadiene and 7-oxabicyclo[2.2.1] hepta-2,5-diene-2,3-dicarboxylate
}

\author{
Özgür Yılmaz ${ }^{\oplus}$ and Nermin Şimşek Kuş ${ }^{\oplus *}$
}

Department of Chemistry, Faculty of Arts and Sciences, Mersin University, 33343, Mersin, Türkiye

(Received September 28, 2017; Revised November 01, 2017; Accepted November 03, 2017)

\begin{abstract}
The reaction between 1,3-cyclohexadiene and dimethyl 7-oxabicyclo[2.2.1]hepta-2,5-diene-2,3dicarboxylate both without a catalyst and with different catalysts, in both atmospheric and at high pressure, over 20 days were studied. At the end of the reactions, different products (retro Diels-Alder addition product $\mathbf{5}$ and Diels-Alder addition product 6) were obtained in different yields. When we look at the percentage of the addition product, it is observed that the yield of reaction at high pressure in water is the highest. All structures of these products were characterized by ${ }^{1} \mathrm{H}-\mathrm{NMR},{ }^{13} \mathrm{C}-\mathrm{NMR}$, MS, and IR spectroscopy.
\end{abstract}

Keywords: Green chemistry; Diels-Alder reactions; catalyst; tetracyclicmolecule. (C2017 ACG Publications. All rights reserved.

\section{Introduction}

The Diels-Alder reaction is very important in terms of constructing simple and complex molecules and it has been widely used to make rings and bicyclic compounds for more than 80 years. ${ }^{1-}$ ${ }^{7}$ Cycloaddition occurs readily if the diene is substituted with electron-donating groups (as -OR, - $\mathrm{NR}_{2}$, etc.), and the dienophile is substituted with electron-withdrawing groups (as $-\mathrm{NO}_{2},-\mathrm{CN}$, -COR, etc.) or if one of them can be easily removed or consumed in a subsequent reaction. ${ }^{8}$ The Diels-Alder reaction can be reversible; this reaction is called the retro Diels-Alder reaction and is used to synthesize strained, interesting olefins. ${ }^{9-13}$ Heterocyclic and polycyclic molecules obtained via Diels-Alder or retro Diels-Alder reactions are very important in organic chemistry and they are used as starting materials in the pharmacology and other fields. In our recent studies, we reported the reaction between 2,3-dimethyl-1,3-butadiene and dimethyl 7-oxabicyclo[2.2.1]hepta-2,5-diene-2,3-dicarboxylate with catalysts, i.e. phenol, acetic acid, nafion, and $\beta$-cyclodextrin. ${ }^{14}$ In the present study, we extended the Diels-Alder reaction between 1,3-cyclohexadiene (4) and dimethyl 7-oxabicyclo[2.2.1]hepta-2,5diene-2,3-dicarboxylate (3) with different catalysts (phenol, acetic acid, nafion, $\beta$-cyclodextrin) and also without a catalyst at 25 and $55^{\circ} \mathrm{C}$ (Figure 1). Furthermore, this addition reaction was studied at different temperatures $\left(25\right.$ and $\left.55^{\circ} \mathrm{C}\right)$ high pressure in water. (Table 1). There are examples of DielsAlder studies in water in the literature. ${ }^{15,16}$ This is important for green chemistry.

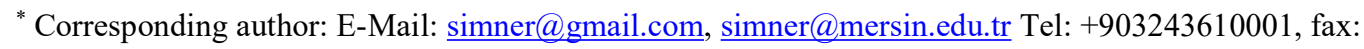
$+903243610046$
} 


\section{Experimental}

\subsection{Materials and Apparatus}

Melting points were determined with a Mettler Toledo MP90 melting point system and were not corrected. Infrared spectra were recorded on a Perkin Elmer Win First ${ }^{\circledR}$ Satellite. The ${ }^{1} \mathrm{H}$ and ${ }^{13} \mathrm{C}$ NMR spectra were recorded on a Bruker Ultrashield Plus Biospin GmbH $400 \mathrm{MHz}$ spectrometer. All chemical shifts $(\delta)$ were reported in ppm from internal TMS. Column chromatography was performed on silica gel (Kiesel-gel 60, 230-400 mesh, Merck). TLC was carried out on Merck $0.2 \mathrm{~mm}$ silica gel $60 \mathrm{~F}_{254}$ analytical aluminum plates.

\subsection{Synthesis of Dimethyl 7-oxo-bicyclo[2.2.1] hepta-2,5-diene-2,3-dicarboxylate (3)}

Dimethyl 7-oxo-bicyclo[2.2.1]hepta-2,5-diene-2,3-dicarboxylate (3) was prepared as described in the literatüre. ${ }^{17-19}$

\subsection{General Procedure for the Cycloaddition Reaction with Different Catalysts and Without Catalysts}

Dienophile 3 (0.5 g, $2.4 \mathrm{mmol})$ and 1,3-cyclohexadiene (4) (0.197 g, $2.4 \mathrm{mmol})$ were dissolved in $10 \mathrm{~mL}$ of chloroform, and then the reaction was stirred at room temperature for 20 days. After the reaction, the solvent was removed. Then, the mixture of the products and starting molecules was separated with chromatography on $50 \mathrm{~g}$ of silica gel eluting with ethyl acetate/hexane (1:3). At the end of the purification retro-Diels Alder product 5 and addition product 6 were obtained. $10 \mathrm{mg}$ of catalyst was added to the reaction medium in the catalyzed experiments.

(1R,4S)-dimethyl bicyclo[2.2.2]octa-2,5-diene-2,3-dicarboxylate $(5)^{20}$ : Colorless oil. ${ }^{1} \mathrm{H}$ NMR $\left(400 \mathrm{MHz}, \mathrm{CDCl}_{3}\right): \delta=6.31(\mathrm{~s}, 2 \mathrm{H}), 3.96(\mathrm{~s}, 2 \mathrm{H}), 3.7(\mathrm{~s}, 6 \mathrm{H}), 1.41$ (AA 'part of AA 'BB 'system, quasi d, $J=6.8 \mathrm{~Hz}, 2 \mathrm{H}), 1.33 \mathrm{~B}$ part of AB system (BB 'part of AA 'BB 'system, quasi, d $J=6.8$ $\mathrm{Hz}, 2 \mathrm{H}){ }^{13} \mathrm{C} \mathrm{NMR}\left(100 \mathrm{MHz}, \mathrm{CDCl}_{3}\right): \delta=166.5,142.2,133.6,52.1,38.9,24.5$. Calc. for $\mathrm{C}_{12} \mathrm{H}_{14} \mathrm{O}_{4}: \mathrm{C}_{\text {, }}$ $64.85 ; \mathrm{H}, 6.35 \%$. Found: $\mathrm{C}, 64.71 ; \mathrm{H}, 6.28$.

(1R,4S,5S,8R,8aR)-dimethyl $\quad$ 1,4,4a,5,8,8a-hexahydro-1,4-epoxy-5,8-ethanonaphthalene-2,3dicarboxylate (6): Colorless oil. FTIR $\left(\mathrm{cm}^{-1}\right): \mathrm{v}=2936,2866,1716,1633,1434,1327,1265,1243$, 1217, 1094, 923. ${ }^{1} \mathrm{H}$ NMR (400 MHz, $\left.\mathrm{CDCl}_{3}\right): \delta=6.15$ (dd, $\left.J=4.8,3.2,2 \mathrm{H}\right), 4.91(\mathrm{~s}, 2 \mathrm{H}), 3.81$ (s, $6 \mathrm{H}), 2.80(\mathrm{~m}, 2 \mathrm{H}), 2.01(\mathrm{~s}, 2 \mathrm{H}), 1.53$ (AA 'part of AA 'BB 'system, quasi d, $J=18.0 \mathrm{~Hz}, 2 \mathrm{H}$ ), $1.24(\mathrm{BB}$ 'part of AA 'BB 'system, quasi d, $J=18.0 \mathrm{~Hz}, 2 \mathrm{H}),{ }^{13} \mathrm{C} \mathrm{NMR}\left(100 \mathrm{MHz}, \mathrm{CDCl}_{3}\right)$ : $\delta=$ 163.2, 144.5, 131.9, 84.3, 52.2, 43.9, 32.9, 25.1, MS $m / z: 290\left(\mathrm{M}^{+}\right), 259,258\left(\mathrm{M}^{+},-\mathrm{OCH}_{3}\right), 229,230$ $\left(\mathrm{M}^{+},-\mathrm{C}=\mathrm{O}\right), 199,198,197\left(\mathrm{M}^{+},-\mathrm{OCH}_{3}\right), 185,184\left(\mathrm{M}^{+},-\mathrm{O}\right), 154,153,152\left(\mathrm{M}^{+},-\mathrm{C}=\mathrm{O}\right)$. Calc. for: $\mathrm{C}_{16} \mathrm{H}_{18} \mathrm{O}_{5}: \mathrm{C}, 66.19 ; \mathrm{H}, 6.25 \%$. Found: $\mathrm{C}, 66.10 ; \mathrm{H}, 6.19$

\subsection{Procedure for the Cycloaddition Reaction at High Pressure and in Hot Water ${ }^{21}$}

Diene 3 (0.5 g, $2.4 \mathrm{mmol})$ and 1,3-cyclohexadiene (4) (0.197 g, $2.4 \mathrm{mmol})$ were dissolved in $20 \mathrm{~mL}$ of water in a stainless steel pressure reactor, and then the reaction was stirred at $40 \mathrm{bar}_{2}$ and different temperature $\left(25\right.$ and $\left.50{ }^{\circ} \mathrm{C}\right)$ for 20 days. After the completion of the reaction it was extracted with EtOAc $(3 \times 10 \mathrm{~mL})$ and dried over $\mathrm{MgSO}_{4}$. The solvent was evaporated on a rotary evaporator under reduced pressure. Then the product was chromatographed over silica gel using ethyl acetate:hexane (1:3) as the eluent to separate the product. At the end of the purification retro DielsAlder product 5 and addition product $\mathbf{6}$ were obtained. 


\section{Results and Discussion}

At the beginning, furan (1) and dimethyl acetylene dicarboxylate (2) were reacted, and produced dimethyl 7-oxa-bicyclo[2.2.1] hepta-2,5-diene-2,3-dicarboxylate (3) ${ }^{17,18}$ in high yield (Scheme 1).

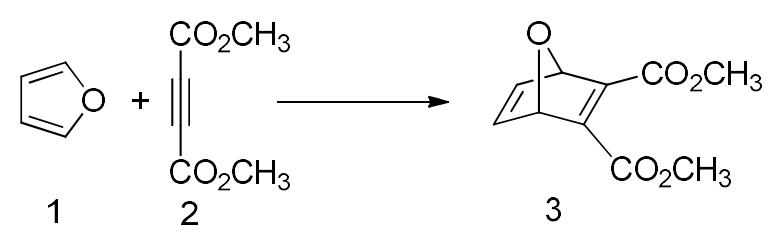

Scheme 1. The synthesis of dienophile 3 . $^{17,18}$

After the synthesis of dienophiles 3 (1.0 eq.) dienophile 3 was reacted with 1,3cyclohexadiene (4) (1.0 eq.) in $\mathrm{CHCl}_{3}$ without a catalyst at room temperature for 20 days; it was observed that very little product, retro Diels-Alder addition product $5(5 \%)$ and Diels-Alder addition product $6(9 \%)$, formed.

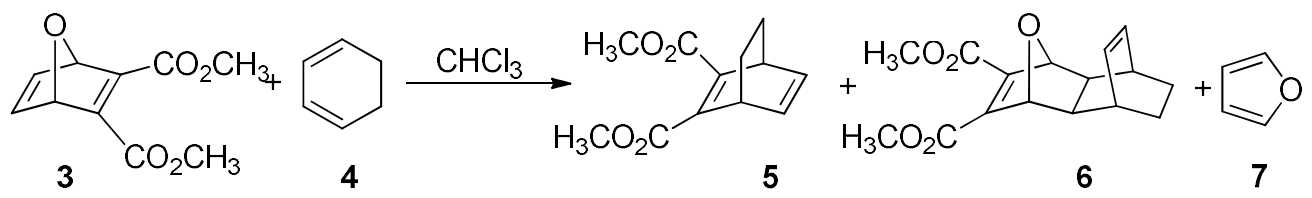

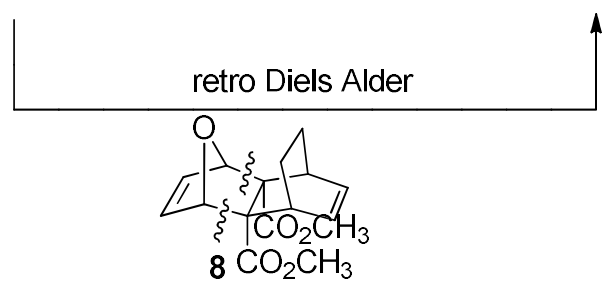

Scheme 2. Diels-Alder reaction of dienophile 3 with diene 4.

Intermediate product (addition product over electron-deficent doule bond) $\mathbf{8}$ is thermally unstable and breakage of the $\mathrm{C}-\mathrm{C}$ bond results in retro Diels-Alder addition product 5 (Scheme 2). Thus, there are addition at both electron-deficent double bond and electron-rich double bond. There are similar examples in the literatüre. McCulloch et al. ${ }^{22}$ examined influence of Lewis acids on the Diels-Alder reaction and synthesized addition products over both electron-deficent double bond and electron-rich double bond at $100{ }^{\circ} \mathrm{C}$.

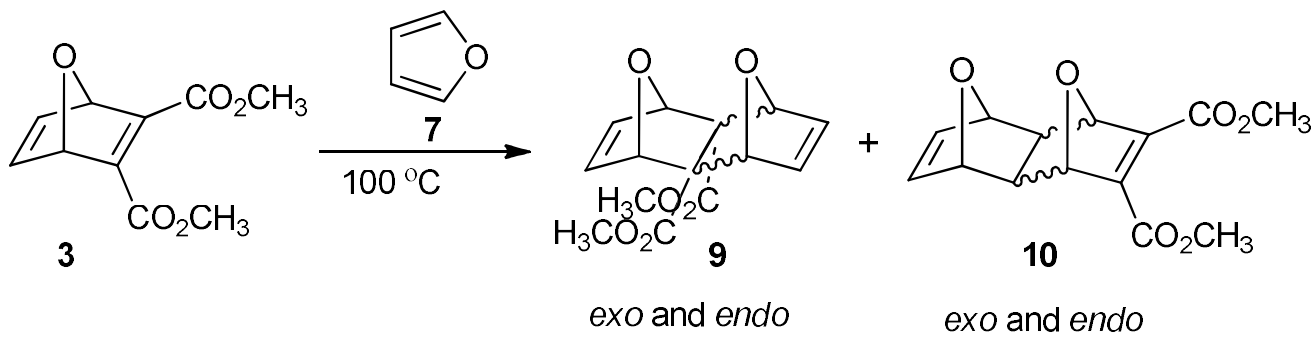

Scheme 3. Diels-Alder reaction of dienophile 3 with diene $7 .^{22}$ 


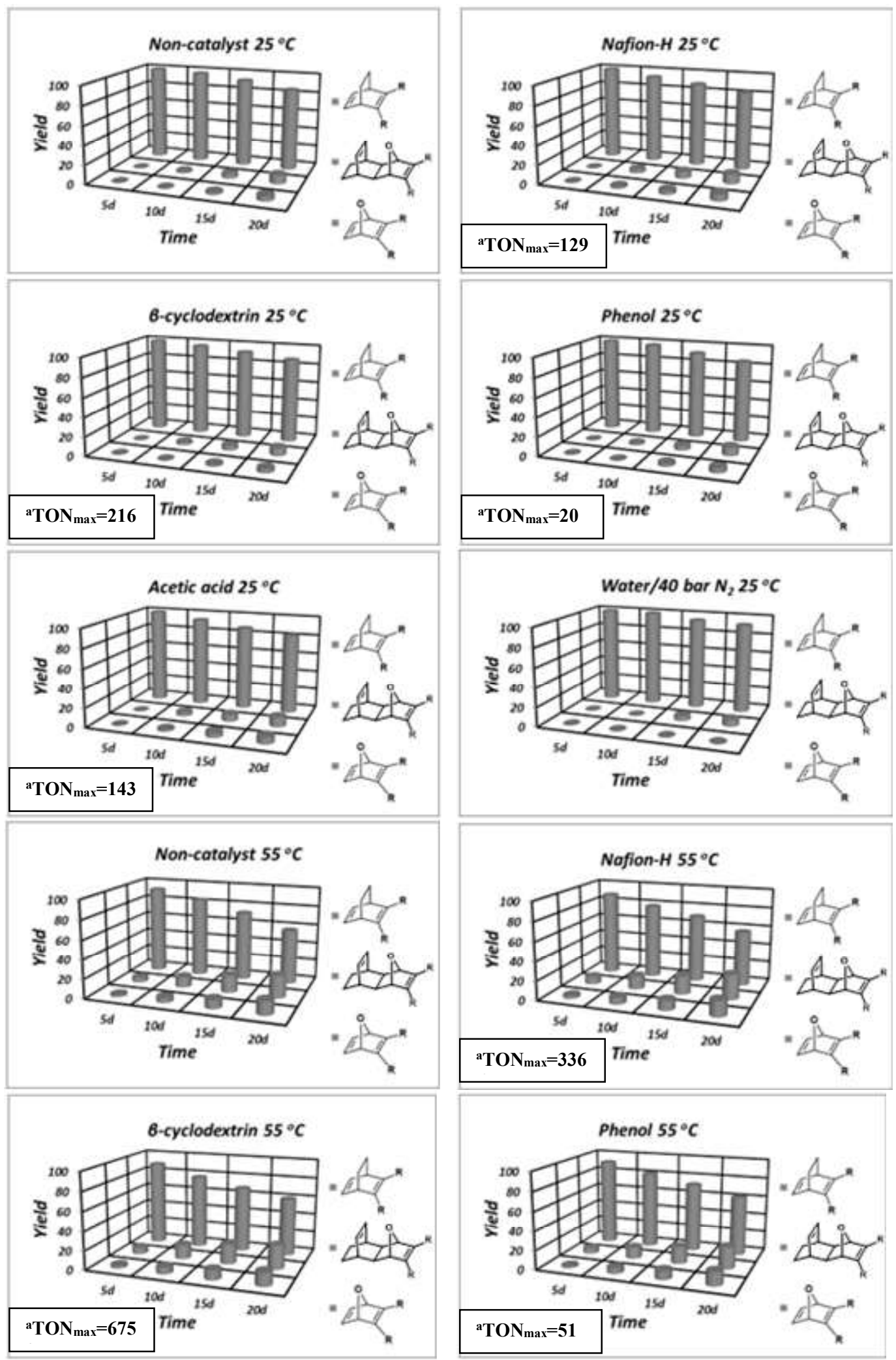

a Turnover number $(\mathrm{TON})=[($ moles of limiting reactant $($ dienophile 3$)) /$ moles of catalyst $] \mathrm{x}$ yield $(20 \mathrm{~d})$

Figure 1. Diels-Alder reaction of dienophile 3 and diene 4 
To increase the yield, we decided to use different catalysts in this reaction (Table1). Phenol, acetic acid, nafion and $\beta$-cyclodextrin, were used as the catalyst (Figure 1). Two products, $\mathbf{5}^{20}$ and $\mathbf{6}$, were obtained at the end of the reaction. Given the amount of product, it was observed that the catalyst alone was not effective. The results were similar to those of the reaction at room temperature. We decided to increase the reaction temperature. Increasing the temperature and using the catalyst increased the yield of the reaction very little, but that was not enough for us. Finally, when the reaction was performed at high pressure and in hot water, we saw that the yield of Diels-Alder addition product 6 was $61 \%$ (Figure 1). When we brought the conditions to high pressure and in hot water (40 Bar, 120 ${ }^{\circ} \mathrm{C}$ ), we saw that the molecule has completely disintegrated.

There are 4 signals, three singlets $\left(-\mathrm{CH}=,-\mathrm{CH}\right.$, and $\left.-\mathrm{OCH}_{3}\right)$ and one $\mathrm{AB}$ system $\left(-\mathrm{CH}_{2} \mathrm{CH}_{2}\right)$ as a quasi doublet $(J=6.8 \mathrm{~Hz})$ in the ${ }^{1} \mathrm{H}$ NMR spectra of retro Diels-Alder addition product 5 . The ${ }^{1} \mathrm{H}$ NMR spectra of Diels-Alder addition product $\mathbf{6}$ have four signals. However, the exact structure of Diels-Alder addition product $\mathbf{6}$ was found by the COSY and NOESY NMR result. Diels-Alder addition product $\mathbf{6}$ shows that the oxygen and the double bond are on the same side. The double bond proton does not interact with bridge protons, because it is not in the same space.

Table 1. Diels-Alder reaction of dienophile 3 and diene 4 in various conditions

\begin{tabular}{|c|c|c|c|c|c|c|c|c|c|}
\hline \multirow{3}{*}{$\begin{array}{l}\text { Reaction } \\
\text { Conditions }\end{array}$} & \multirow[t]{3}{*}{ Product } & \multicolumn{8}{|c|}{ Yield\% } \\
\hline & & \multicolumn{4}{|c|}{$25^{\circ} \mathrm{C}$} & \multicolumn{4}{|c|}{$55^{\circ} \mathrm{C}$} \\
\hline & & 5d & 10d & 15d & 20d & 5d & 10d & 15d & 20d \\
\hline \multirow[t]{3}{*}{ No catalyst } & 3 & 100 & 98 & 93 & 86 & 93 & 84 & 73 & 63 \\
\hline & 5 & -- & -- & 2 & 5 & 2 & 5 & 9 & 14 \\
\hline & 6 & -- & 2 & 5 & 9 & 5 & 11 & 18 & 23 \\
\hline \multirow[t]{3}{*}{ Nafion-H } & 3 & 100 & 94 & 89 & 83 & 89 & 79 & 71 & 58 \\
\hline & 5 & -- & 2 & 4 & 7 & 3 & 7 & 10 & 16 \\
\hline & 6 & -- & 4 & 7 & 10 & 8 & 14 & 19 & 26 \\
\hline \multirow[t]{3}{*}{$\beta$-cyclodextrin } & 3 & 100 & 97 & 93 & 88 & 90 & 78 & 69 & 61 \\
\hline & 5 & -- & -- & 2 & 4 & 3 & 7 & 10 & 14 \\
\hline & 6 & -- & 3 & 5 & 8 & 7 & 15 & 21 & 25 \\
\hline \multirow[t]{3}{*}{ Phenol } & 3 & 100 & 98 & 92 & 86 & 92 & 82 & 73 & 63 \\
\hline & 5 & -- & -- & 3 & 5 & 2 & 6 & 9 & 14 \\
\hline & 6 & -- & 2 & 5 & 9 & 6 & 12 & 18 & 23 \\
\hline \multirow[t]{3}{*}{ Acetic acid } & 3 & 100 & 94 & 88 & 83 & 86 & 74 & 65 & 54 \\
\hline & 5 & -- & 2 & 5 & 7 & 5 & 9 & 13 & 17 \\
\hline & 6 & -- & 4 & 7 & 10 & 9 & 17 & 22 & 29 \\
\hline \multirow[t]{3}{*}{ Water/40 bar $\mathrm{N}_{2}$} & 3 & 100 & 100 & 95 & 93 & 80 & 59 & 45 & 25 \\
\hline & 5 & -- & -- & -- & -- & 3 & 7 & 10 & 14 \\
\hline & 6 & -- & -- & 5 & 7 & 17 & 34 & 45 & 61 \\
\hline
\end{tabular}

\section{Conclusion}

In summary, we achieved the chemoselective and exo-diastereo selective reaction between 1,3-cyclohexadiene and dimethyl 7-oxabicyclo[2.2.1]hepta-2,5-diene-2,3-dicarboxylate without a catalyst, with small amounts of catalyst (nafion, $\beta$-cyclodextrin phenol and acetic acid), and in water ( 40 bar $\mathrm{N}_{2}, 55^{\circ} \mathrm{C}$ ). It was observed in the reaction that the effect of the catalyst was absent, the highest yield was at 40 bar atmosphere and $55^{\circ} \mathrm{C}$, it was the effect of the pressure (Table 1). The syntheses in water have potentially abundant applications, and it is hoped that this paper will motivate such efforts. 


\section{Acknowledgements}

The authors are indebted to Mersin University (2015-AP4-1235 and 2017-2-AP52502) for their financial support to this work.

\section{Supporting Information}

Supporting information accompanies this paper on http://www.acgpubs.org/OC

\section{ORCID}

Özgür Y1lmaz: 0000-0001-9278-1091

Nermin Şimşek Kuş: 0000-0002-5402-2614

\section{References}

[1] Fringuelli, F.; Taticchi, A. The Diels-Alder reaction: Selected Practical Methods, Wiley, Chichester, UK 2002.

[2] Trost, B. M. The atom economy-a search for synthetic efficiency. Science. 1991, 254, 1471-1477.

[3] Trost B. M. Atom Economy-A Challenge for Organic Synthesis: Homogeneous catalysis leads the way. Angew. Chem. Int. Ed. 1995, 34, 259-281.

[4] Corey, E. J. Catalytic enantioselective Diels-Alder reactions: methods, mechanistic fundamentals, pathways, and applications. Angew. Chem. Int. Ed. 2002, 41, 1650-1667.

[5] Nicolaou, K. C.; Snyder, S. A.; Montagnon, T.; Vassilikogiannakis, G. E. The Diels-Alder reaction in total synthesis. Angew. Chem. Int. Ed. 2002, 41, 1668-1698.

[6] Stocking, E. M.; Williams, R. M. Chemistry and biology of biosynthetic Diels-Alder reactions. Angew. Chem. Int. Ed. 2003, 42, 3078-3115.

[7] Menzek, A.; Kelebekli, L.; Altundaş, A; Şahin, E.; Polat F. Cycloaddition reaction of 1,4dihydronaphthalene 1,4-epoxide with cyclooctatetraene: Cope rearrangement in an adduct. Helv. Chim. Acta 2008, 91, 2367-2378.

[8] Tietze, L. F. Domino reactions in organic synthesis. Chem. Rev. 1996, 96, 115-136.

[9] Diels, O.; Thiele, W. E. Zur kenntnis der dien-synthesen, XXX. Mitteil.: Über das chlorid der acetylendicarbonsäure. Eur. J. Inorg. Chem. 1938, 71, 1173-1178.

[10] Ripoll, J. L.; Rouessac, A.; Rouessac, F. Applications recentes de la reaction de retro-Diels-Alder en synthese organique. Tetrahedron. 1978, 34, 19-40.

[11] Sauer, J. Diels-Alder reactions II: The reaction mechanism. Angew. Chem. Int. Ed. Engl. 1967, 5, 229268.

[12] Kwart, H.; King, K. The reverse Diels-Alder or retro Diels Alder reaction. Chem. Rev. 1968, 68, 415447.

[13] Lasne, M-C.; Ripoll, J. L. New synthetic developments of the $[4 \pi+2 \pi]$ cycloreversion. Synthesis. 1985 , 121-143.

[14] Yilmaz, Ö.; Simsek Kus, N.; Tunç, T.; Sahin, E. Diels-Alder reactions: The effects of catalyst on the addition reaction. J. Molecular Struc. 2015, 1098, 72-75.

[15] Girish, Y. R.; Pandit, S.; Pandit, S.; De M. Graphene oxide as a carbocatalyst for a Diels-Alder reaction in an aqueous medium. Chem. Asian J. 2017 12(18), 2393-2398.

[16] Shionozaki, N.; Iwamura, N.; Tanaka R.; Makino K.; Uchiro H. Total synthesis of diaporthichalasin by using the intramolecular Diels-Alder reaction of an $\alpha, \beta$-unsaturated $\gamma$-hydroxylactam in aqueous media. Chem. Asian J. 2013, 8(6), 1243-1252.

[17] Şimşek, N.; Arici, C.; McKee, M. L.; Dinçer, Ü.; Balci, M. High-temperature bromination XIII [1]: Bromination of dimethyl 7-oxabicyclo[2.2.1] hepta-2,5-diene-2,3-dicarboxylate. Struct. Chem. 2001, 12, 305-311.

[18] Yılmaz, Ö.; Şimşek Kuş, N.; Küce, P.; Coral ,G.; Çelik, A.; Gültekin, M-S. Simple and convenient preparation of some bicyclic alcohols and epoxide derivatives: Promising antibiotic activities of (rac)dimethyl 3,8-dioxatricyclo[3.2.1.02,4]oct-6-ene-6,7-dicarboxylate. Med. Chem. Res. 2015, 24(6), 27092716.

[19] Valiulin, R. A.; Arisco, T-M.; Kutateladze, A. G. Photoinduced intramolecular cyclopentanation vs photoprotolytic oxametathesis in polycyclic alkenes outfitted with conformationally constrained aroylmethyl chromophores. J. Org. Chem. 2013, 78, 2012-2025. 
[20] Galanin, N. E.; Shaposhnikov G. P.; Koifman O. I. Methods for synthesis of meso-substituted tetrabenzoporphyrins. Russ. Chem. Rev., 2013, 82(5), 412-428.

[21] Simsek Kus, N. One-step synthesis of substituted isobenzofuran-1(3H)-ones and isobenzofuran-1,3diones from indane derivatives in subcritical media. Monatsh. Chem. 2013, 144, 1183-1186.

[22] McCulloch, A.W.; Smith, D. G.; McInnes A. G. Influence of Lewis Acids on the Diels-Alder Reaction. V. The Reaction of Furan with Dimethyl Acetylenedicarboxylate. Can. J. of Chem., 1973, 51(24), 41254136
A C G
publications
(C) 2017 ACG Publications 